\section{RESEARCH ARTICLE \\ 10.1029/2019JC015063 \\ Numerical Assessment of Infragravity Swash Response to Offshore Wave Frequency Spread Variability}

Key Points:

- Numerical simulations reveal that frequency spread affects swash amplitudes with a pattern that inverts over two Iribarren number ranges

- An infragravity swash increase for increasing frequency spread is observed under moderately dissipative conditions

- The infragravity swash increases for decreasing frequency spread under extremely dissipative conditions

Correspondence to:

A. Ruju,

andrea.ruju@ite-fem.org

Citation:

Ruju, A., Lara, J. L., \& Losada, I. J. (2019). Numerical assessment of infragravity swash response to offshore wave frequency spread variability. Journal of Geophysical Research: Oceans, 124, 6643-6657. https://doi. org/10.1029/2019JC015063

Received 16 FEB 2019

Accepted 3 AUG 2019

Accepted article online 8 AUG 2019

Published online 10 SEP 2019

(C)2019. American Geophysical Union. All Rights Reserved.

\author{
Andrea Ruju ${ }^{1,2}\left(\mathbb{D}\right.$, Javier L. Lara ${ }^{3}(\mathbb{D})$, and Inigo J. Losada ${ }^{3}(\mathbb{D}$ \\ ${ }^{1}$ Department of Chemical and Geological Sciences, University of Cagliari, Cittadella Universitaria, Cagliari, Italy, \\ ${ }^{2}$ France Energies Marines, Batiment Cap Ocean, Technopole Brest Iroise, Plouzane, France, ${ }^{3}$ Environmental \\ Hydraulics Institute "IH Cantabria”, Universidad de Cantabria, Santander, Spain
}

\begin{abstract}
We use a numerical model, already validated for this purpose, to simulate the effect of wave frequency spread on wave transformation and swash amplitudes. Simulations are performed for planar beach slope cases and for offshore wave spectra whose frequency spread changes over realistic values. Results indicate that frequency spread, under normally approaching waves, affects swash amplitudes. For moderately dissipative conditions, the significant infragravity swash increases for increasing values of the offshore frequency spread. The opposite occurs under extremely dissipative conditions. The numerical analysis suggests that this inverted pattern is driven by the effect that different distributions of incoming long-wave energy have on low-frequency wave propagation and dissipation. In fact, with large frequency spreads, wave groups force relatively short subharmonic waves that are strongly enhanced in the shoaling zone. This process leads to an infragravity swash increase for increasing frequency spread under moderately dissipative conditions in which low-frequency energy dissipation in shallow water is negligible or small. However, under extremely dissipative conditions, the significant low-frequency energy dissipation associated with large frequency spreads overturns the strong energy growth in the shoaling zone eventually yielding an infragravity swash decrease for increasing frequency spread.
\end{abstract}

\section{Introduction}

As a result of the interaction with the seabed, a rapid evolution of wave properties occurs in the nearshore with waves changing their shape, breaking and finally driving shoreline/runup oscillations in the swash region (Elfrink \& Baldock, 2002). Understanding and predicting runup oscillations have been a research topic for decades considering that the motion of water running up and down the beach drives change in the morphology (Butt \& Russell, 2000), affects infiltration (Horn, 2002; Turner \& Masselink, 1998), is relevant to ecological studies dealing with the distribution of macrofauna (McArdle \& McLachlan, 1992), and its estimation is needed to define coastal hazards and setback lines (Vousdoukas et al., 2012). Our predictive capability of runup elevation $R$ remains far from optimal, and scatter is present in the predictor commonly used (Stockdon et al., 2006). The predictor of $R$ has been obtained using 10 data sets and developing a linear regression between $R$ and offshore variables (like significant wave height $H_{s 0}$ and wavelength $L_{0}$ ) and beach slope $\beta$. A combination of these parameters is the Iribarren number, $\xi_{0}=\beta / \sqrt{H_{s 0} / L_{0}}$.

Swash $S(t)$ represents the fluctuating part of runup $R(t)$ and can be separated into the sum of two components representing the contribution of the incident sea-swell $S S$ and infragravity $I G$ frequency bands (for oceanic waves, separation is usually set at a frequency of 0.04 or $0.05 \mathrm{~Hz}$ ). Guza and Thornton (1982) first showed that on gently sloping beaches (in their experiment foreshore beach slopes ranged 0.03-0.05), the SS component of swash $S_{\mathrm{SS}}$ saturates (it does not increase with $H_{\mathrm{s} 0}$ ), while the IG component $S_{\mathrm{IG}}$ continues to grow and becomes the primary contribution to the overall swash motion. In recent years, a considerable number of field, laboratory, and numerical studies have tackled a variety of aspects of processes related to low-frequency swash and its variability.

Observations under extremely dissipative conditions (typically $\xi_{0}<0.3$ ) have revealed that saturation is not limited to the SS band (as first reported by Guza \& Thornton, 1982) but might occur also at IG frequencies (Fiedler et al., 2015; Ruessink et al., 1998; Ruggiero et al., 2004; Senechal et al., 2011). Moreover, Guedes et al. (2011) have shown that tidally modulated breaking affects runup response. Laboratory studies have explored surf zone processes such as low-frequency energy growth and dissipation that appear strictly related to the 
IG band saturation of swash. Battjes et al. (2004) and van Dongeren et al. (2007) showed that both the growth rate of shoaling long waves and the long-wave energy dissipation in shallow water are frequency dependent. These investigations introduced the normalized bed slope parameters $\beta_{b}$ and $\beta_{H}$ defined as

$$
\begin{aligned}
& \beta_{b}=\frac{\beta}{\omega} \cdot \sqrt{\frac{g}{h_{b}}}, \\
& \beta_{H}=\frac{\beta}{\omega} \cdot \sqrt{\frac{g}{H}}
\end{aligned}
$$

in which $\omega$ is the radial frequency of the low-frequency wave, $g$ is the gravitational acceleration, $h_{b}$ is the water depth at the short-wave breakpoint, and $H$ is the wave height of the incoming long wave in the inner surf zone. By means of a quantitative energy balance in the shoaling zone, Battjes et al. (2004) reported an increase of the growth rate of long waves from the conservative shoaling (Green law, proportional to $h^{-1 / 4}$ ) for the lower frequencies characterized by a high $\beta_{b}$ to the shallow water equilibrium limit (Longuet-Higgins \& Stewart, 1962, proportional to $h^{-5 / 2}$ ) for the higher frequencies of the IG band characterized by a low $\beta_{b}$. The laboratory experiments of van Dongeren et al. (2007) showed that the similarity parameter $\beta_{H}$ controls long-wave dissipation in shallow water, with a dissipation rate that increases as $\beta_{H}$ decreases below the threshold value of 1.25. It is worth mentioning that an analogous similarity parameter for low-frequency waves was introduced by Baldock et al. (2000) and Baldock and Huntley (2002) to differentiate between a mild slope regime in which bound waves dominate over long waves generated by the breakpoint oscillation (Symonds et al., 1982) and a steep slope regime in which the opposite occurs. Low-frequency dynamics under dissipative conditions were further investigated by more recent laboratory studies in which band saturation suggested breaking at IG frequencies as a dissipative mechanism in shallow water (de Bakker et al., 2015; Padilla \& Alsina, 2017). Besides laboratory investigations, advanced numerical models (Fiedler et al., 2018; Lara et al., 2011; Ruju et al., 2012; Zijlema et al., 2011) have become a powerful tool to explore inner surf zone and swash hydrodynamics. Despite the advances brought by the mentioned research, being able to predict $S_{\mathrm{IG}}$ and the linkages to surf zone hydrodynamics remains a challenge.

All studies discussed so far do not address the variability in runup caused by offshore variability in frequency and directional spreads. The study by Guza \& Feddersen (2012; hereinafter GF12) used a numerical model to explore how runup is affected by changes in the incoming frequency-directional wave energy spectra. GF12 carried out an extensive numerical experiment in which numerical simulations included the following environmental parameter ranges: $0.02-0.04$ for the planar beach slope, $0.4-2.5 \mathrm{~m}$ for the incoming significant wave height, $0.06-0.14 \mathrm{~Hz}$ for the peak frequency, $0.0025-0.02 \mathrm{~Hz}$ for the frequency spread, and $5-30^{\circ}$ for the directional spread. These ranges correspond to Iribarren numbers generally lower than 0.4 , thus indicating dissipative conditions. Numerical simulations indicate that as the frequency spread rises from narrow-banded wave conditions, the associated increase of the bound wave forcing eventually yields a significant $R$ increase. The predictive formula provided by GF12, including parameters that directly account for frequency and directional spread, relies upon the bound wave formalism and does not take into account the influence of shallow water processes. The relevance of the findings by GF12 is such that more investigation is warranted.

Here, we use a numerical approach to focus on the role of frequency spread on $S_{\text {IG }}$ oscillations under a range of beach slopes and unidirectional wave conditions, including more dissipative conditions than those analyzed by GF12. The main goal of this paper is to understand how and why different $S_{\text {IG }}$ responses to frequency spread variations can be observed under different Iribarren number ranges. With this aim, we try to relate the observed swash patterns to the propagation regimes (Battjes et al., 2004; van Dongeren et al., 2007) characterizing low-frequency waves over sloping bottoms.

\section{Wave Characteristics and Beach Geometry}

Incoming conditions and bathymetry profiles are chosen referring back to the geometry of the GLOBEX experiment (Ruessink et al., 2013) carried out in the Scheldt flume (The Netherlands). Ruju et al. (2014), de Bakker et al. (2016), and Mendes et al. (2018) successfully used the SWASH model (Zijlema et al., 2011) to numerically reproduce the swash and long-wave dynamics observed in the experiment. In this study, we use SWASH with a numerical setup similar to that adopted by Ruju et al. (2014). 
Table 1

Simulated Wave Cases

\begin{tabular}{lccccccc}
\hline \multicolumn{7}{c}{ Random waves } \\
\hline Run & $\xi_{0}$ & $H_{s 0}(\mathrm{~m})$ & $H_{s}(\mathrm{~m})$ & $t_{p}(\mathrm{~s})$ & $\beta$ & $\gamma$ & $U_{r}$ \\
\hline R1, R13, R25, R37 & 0.08 & 0.137 & 0.125 & 1.90 & $1: 80$ & $1,3.3,8,13$ & 4.34 \\
R2, R14, R26, R38 & 0.10 & 0.096 & 0.088 & 1.99 & $1: 80$ & $1,3.3,8,13$ & 3.47 \\
R3, R15, R27, R39 & 0.12 & 0.057 & 0.052 & 1.83 & $1: 80$ & $1,3.3,8,13$ & 1.61 \\
R4, R16, R28, R40 & 0.14 & 0.040 & 0.037 & 1.79 & $1: 80$ & $1,3.3,8,13$ & 1.08 \\
R5, R17, R29, R41 & 0.16 & 0.100 & 0.092 & 1.62 & $1: 40$ & $1,3.3,8,13$ & 2.00 \\
R6, R18, R30, R42 & 0.20 & 0.080 & 0.073 & 1.81 & $1: 40$ & $1,3.3,8,13$ & 2.21 \\
R7, R19, R31, R43 & 0.24 & 0.051 & 0.047 & 1.74 & $1: 40$ & $1,3.3,8,13$ & 1.26 \\
R8, R20, R32, R44 & 0.28 & 0.053 & 0.048 & 2.06 & $1: 40$ & $1,3.3,8,13$ & 2.11 \\
R9, R21, R33, R45 & 0.32 & 0.137 & 0.125 & 1.90 & $1: 20$ & $1,3.3,8,13$ & 4.35 \\
R10, R222, R34, R46 & 0.40 & 0.066 & 0.061 & 1.64 & $1: 20$ & $1,3.3,8,13$ & 1.36 \\
R11, R23, R35, R47 & 0.48 & 0.064 & 0.058 & 1.94 & $1: 20$ & $1,3.3,8,13$ & 2.17 \\
R12, R24, R36, R48 & 0.56 & 0.050 & 0.046 & 2.01 & $1: 20$ & $1,3.3,8,13$ & 1.89 \\
& & \multicolumn{7}{c}{ Bichromatic waves } & & & \\
Run & $\xi_{0}$ & $a_{1}(\mathrm{~m})$ & $a_{2}(\mathrm{~m})$ & $f_{m b}(\mathrm{~Hz})$ & $\beta$ & $\Delta f[\mathrm{~Hz}]$ & $U_{r}$ \\
B1, B37 & 0.08 & 0.031 & 0.031 & 0.53 & $1: 80$ & $0.118,0.046$ & 4.34 \\
B9, B45 & 0.32 & 0.031 & 0.031 & 0.53 & $1: 20$ & $0.118,0.046$ & 4.34 \\
\hline
\end{tabular}

Note. $\xi_{0}$ : Iribarren number; $H_{s 0}$ : significant wave height in deep water; $H_{s}$ : significant wave height at the generation location $(h=0.85 \mathrm{~m}) ; t_{p}$ : peak wave period; $\beta$ : beach slope; $\gamma$ : peak enhancement factor; $U_{r}$ : Ursell number at the generation location; $a_{1}$ and $a_{2}$ : wave amplitudes; $f_{m b}$ and $\Delta f$ : mean and difference frequency of bichromatic waves.

\subsection{Numerical Setup}

Waves are generated at the offshore boundary (water depth $h$ of $0.85 \mathrm{~m}$ ). The seabed profile has a constant depth region $16.57 \mathrm{~m}$ long extending up to the toe of the planar slope. The slope reaches the end of the spatial domain. The beach slope $\beta$ is varied in order to consider different profiles ranging from gentle sloping (1:80, same as in the GLOBEX experiment) to moderately reflective (1:20). An Iribarren number data set including 12 values from 0.08 to 0.56 is obtained by combining three beach slopes (1:20,1:40, and 1:80) and four offshore wave steepness values $H_{s 0} / L_{0}(0.0080,0.0109,0.0156$, and 0.0244$)$. For each $\xi_{0}$, the peak period $t_{p}=1 / f_{p}$ (in which $f_{p}$ is the peak frequency) is randomly chosen in the range 1.6-2.1 s (included in the peak period range adopted in the GLOBEX experiments) and $H_{s 0}$ comes consequently to match the predefined $\xi_{0}$. Finally, the effect of frequency spread is taken into account by varying the peak enhancement factor $\gamma$ of the JONSWAP spectrum between 1 (broad band) and 13 (narrow band). The adopted peak enhancement factor range leads to values of the spectral peakedness parameter $Q_{p}$ (Goda, 1970) comprised between 2.3 and 7.1 which are representative, respectively, of observed broad and narrow incident wave spectra. $Q_{p}$ is defined as

$$
Q_{p}=\frac{2}{\left(\int_{0}^{\infty} E_{\mathrm{tot}}(f) \mathrm{d} f\right)^{2}} \int_{0}^{\infty} f E_{\mathrm{tot}}(f)^{2} \mathrm{~d} f,
$$

where $E_{\text {tot }}(f)$ is the frequency spectrum of the free surface. A total number of 48 random wave simulations $\left(3 \beta \times 4 H_{s 0} / L_{0} \times 4 \gamma\right)$ is considered.

Besides random waves, we simulate four additional bichromatic wave cases. These bichromatic wave runs have the same wave amplitudes $a_{1}$ and $a_{2}$ (with $a_{1}=a_{2}$ ) and the same mean frequency $f_{m b}$. The incoming SS energy and $f_{p}\left(f_{p}=f_{m b}\right)$ match those of the random wave run R1. Moreover, the difference frequency $\Delta f$ of runs $\mathrm{B} 1$ and $\mathrm{B} 9$ matches the mean frequency of the bound wave of run R1 (broad band), whereas $\Delta f$ of runs B37 and B45 matches the mean frequency of the bound wave of run R37 (narrow band). Finally, the beach slope is set to 1:80 for runs B1 and B37, whereas runs B9 and B45 are characterized by a beach slope of 1:20.

Table 1 sums up the random wave and bichromatic runs considered in this paper. The last column of Table 1 reports the Ursell number $U_{r}$ at the generation location. $U_{r}$ is computed as

$$
U_{r}=\frac{H_{s} L^{2}}{h^{3}}
$$



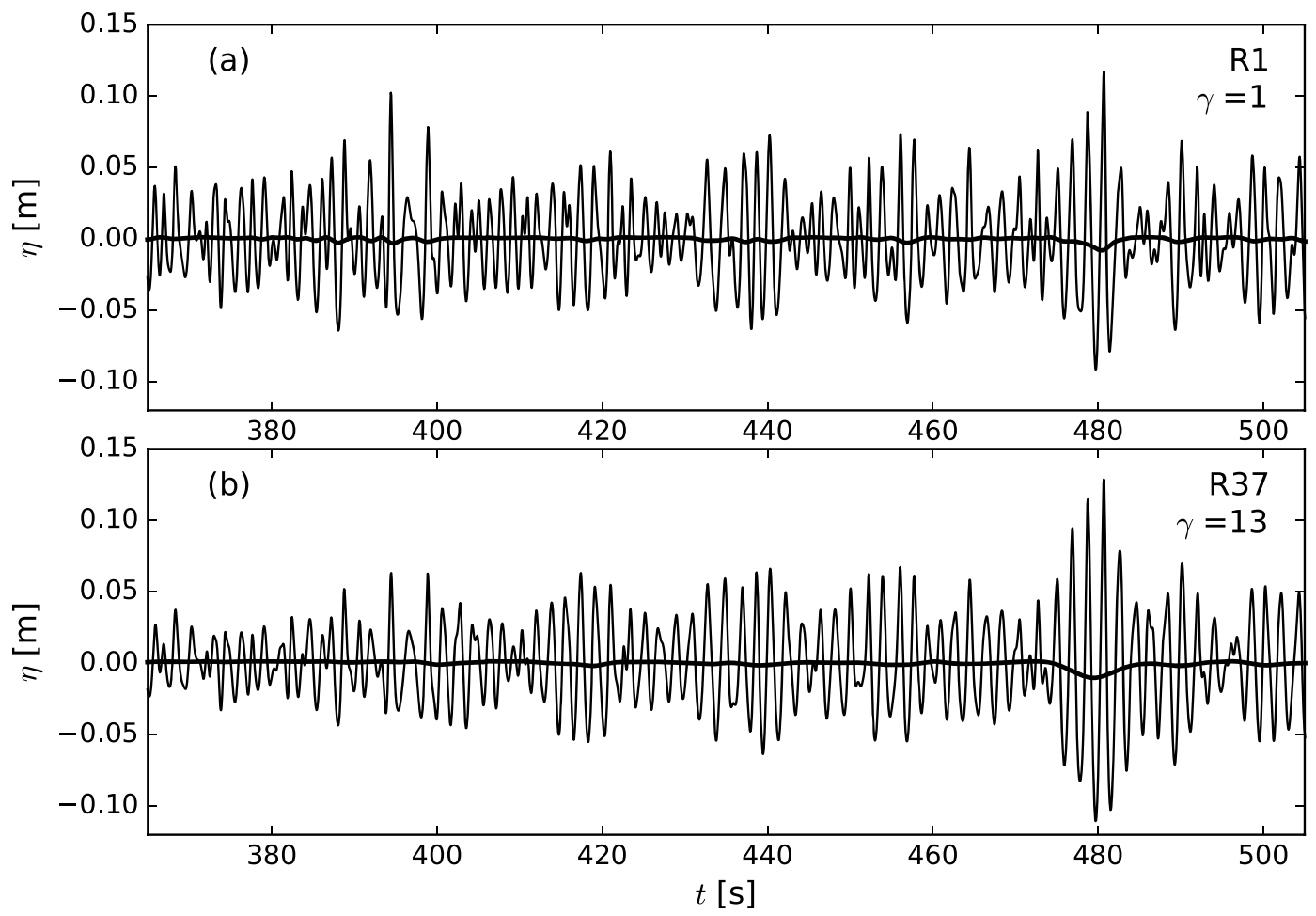

Figure 1. Free surface (thin line) and bound wave (thick line) elevations computed over the horizontal bottom. (a) Runs R1 and (b) R37.

where $L$ is the wavelength of the wave component with frequency $f=f_{p}$, calculated through the dispersion relation. The considered $U_{r}$ range provides values smaller than 4.35. This attests a moderate wave nonlinarity and the validity of the second-order wave theory with all cases that satisfy the condition $h / L_{0}>0.1$ identified by Lo and Dean (1995). Moreover, besides second-order bound waves, the total IG wave field in intermediate water is likely to be constituted by a superposition of bound and free long-wave contributions, since wave groups radiate free long waves as they propagate over a sloping bottom (Baldock, 2006; Lara et al., 2011; Nielsen \& Baldock, 2010). Note that we are neglecting here remote generation and topographic trapping of free long waves that, although significant on natural beaches (Ardhuin et al., 2014; Herbers et al., 1995; Smit et al., 2018), are not relevant in our cross-shore numerical setting. Under these conditions, it would be ideal for the purpose of nearshore wave modeling either to impose both free and bound wave contributions as IG boundary condition in intermediate water or to initialize the wave model in deep water. However, a methodology to quantitatively estimate the free long-wave field generated by wave groups as they propagate from deep water to the generation location in intermediate water is still not available. Moreover, simulating the entire nearshore propagation from deep water would imply a huge increment of computational cost. Nowadays, the second-order wave theory appears to be the best option to initialize the wave model in intermediate water depths provided that the Ursell number and nonlinearity are relatively small. For these reasons, the second-order wave signal is used in this work to minimize the generation of incoming free long waves at the generation location. This methodology is also commonly adopted by numerical and laboratory studies dealing with IG waves (de Bakker et al., 2016; Fiedler et al., 2018; Padilla \& Alsina, 2017). See also the recent work of Fiedler et al. (2019) addressing the role offshore boundary conditions in surf zone modeling.

Figure 1 shows the time series of the free surface and bound wave elevation computed over the horizontal bottom for runs R1 and R37. The second-order bound wave field is calculated with the formulation of Longuet-Higgins and Stewart (1962). It can be observed how the frequency spread determines the wave grouping with run R1 $(\gamma=1)$ characterized by shorter wave groups than run R37 $(\gamma=13)$. 
Horizontal velocities $[\mathrm{m} / \mathrm{s}]$
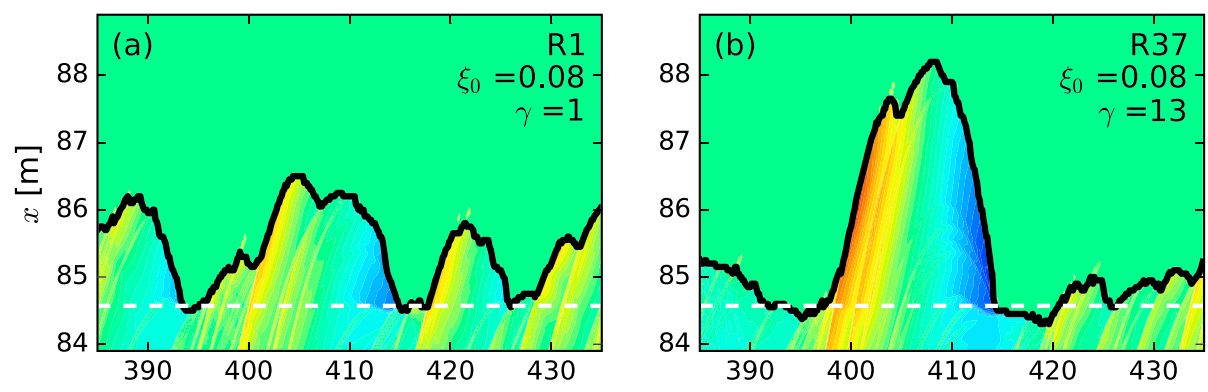

0.8
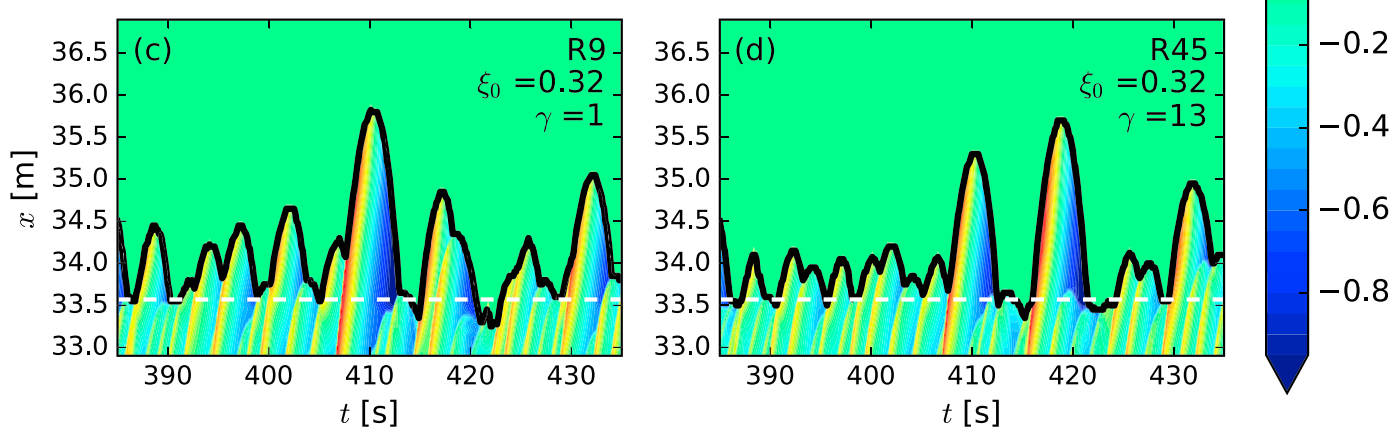

Figure 2. (a-d) Space-time evolution of horizontal velocities in the inner surf and swash zone. The thick black line indicates the runup on the beach face. The dashed line is the still water line.

Reflection of outgoing long waves at the offshore boundary is avoided by turning on the active wave absorption. Each random wave simulation is $1,980 \mathrm{~s}$ long. Numerical simulations are performed using a horizontal grid size $\Delta x$ of $2 \mathrm{~cm}$ (providing values of $L_{0} / \Delta x$ in excess of 150) and two equidistant layers. Although several studies (Barnes \& Baldock, 2010; Chardon-Maldonado et al., 2016; Puleo \& Holland, 2001; Ruju et al., 2016) have reported a friction coefficient variability both in space (across the swash zone) and in time (across wave phases), there is still no consensus about the best method to implement frictional effects into numerical models that do not resolve the bottom boundary layer. For this reason, consistent with previous work dealing with numerical simulations of swash dynamics (Guza \& Feddersen, 2012; Raubenheimer \& Guza, 1996), we adopt here a spatially uniform value of the friction coefficient. A value of 0.011 has been chosen based on considerations about the nature of the bottom in the Globex experiment (Ruju et al., 2014).

Runup is identified as the most landward location where water thickness exceeds $0.003 \mathrm{~m}$. Considering the geometric scale of 1:20 adopted in these experiments (Ruessink et al., 2013), it corresponds to typical elevations of the runup toe $(0.05 \div 0.1 \mathrm{~m})$ detected on natural beaches (Holland et al., 1995; Fiedler et al., 2015). Spectral estimates are obtained by averaging multiple Fourier transforms of $512 \mathrm{~s}$ long, 50\% overlapped segments sampled at $16 \mathrm{~Hz}$. In contrast with previous field studies (Inch et al., 2017; Senechal et al., 2011), a lower cutoff frequency for the IG band of runup is not adopted since in these experiments swash motions are induced exclusively by the incoming wave field, whereas tides and other slow oscillations of the mean water level are not included.

\section{Results}

As a result of the relatively low Iribarren numbers considered in this work $\left(\xi_{0}<0.56\right)$, swash spectra are dominated by oscillations at IG frequencies $\left(f<f_{p} / 2\right)$ showing saturation at incident SS bands $\left(f>f_{p} / 2\right)$. Even in the less dissipative runs, the IG band contains more than $82 \%$ of the total swash variance. Figure 2 shows the horizontal velocity evolution in the inner surf and swash zone for four random wave cases. It can be observed how wave fronts propagate in the inner surf zone eventually driving shoreline oscillations in the swash zone that are especially long over the mild slope of runs R1 and R37. On both slopes 1:20 and 1:80, overlap between sequential swash phases is attested by strong backwash flows that interact with following incoming short waves reducing their wave celerity and preventing their propagation into shallower swash 

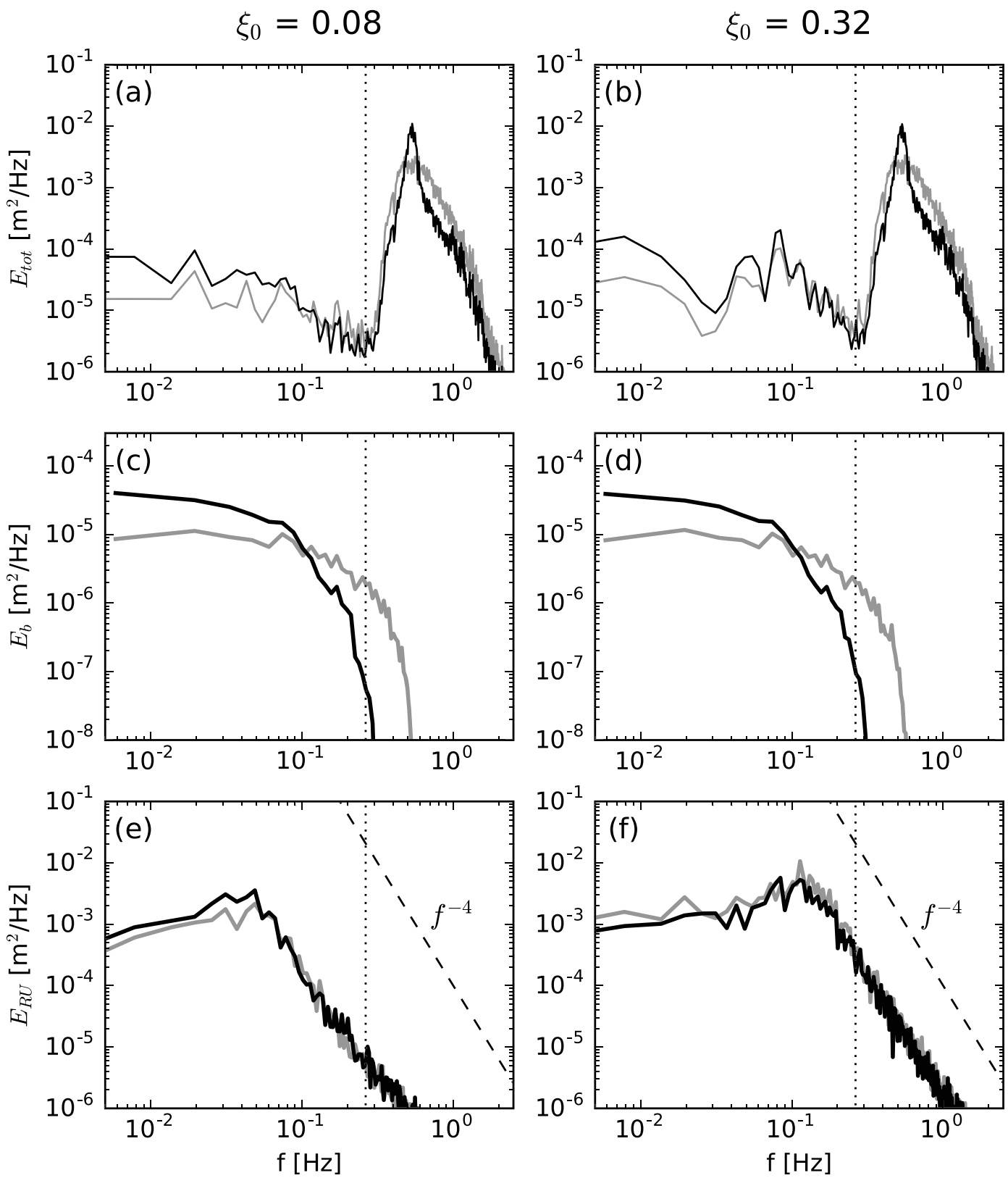

Figure 3. Total wave spectra over the horizontal bottom (a and b). Incident bound wave spectra over the horizontal bottom (c and d). Runup spectra (e and f). Gray and black lines in panels (a), (c), and (e) represent runs R1 $(\gamma=1)$ and $\operatorname{R} 37(\gamma=13)$, respectively. Gray and black lines in panels (b), (d), and (f) represent runs R9 $(\gamma=1)$ and $\operatorname{R} 45(\gamma=13)$, respectively. Dotted lines indicate the limit between infragravity and sea-swell bands.

depths. This is particularly evident in Figures $2 \mathrm{c}$ and $2 \mathrm{~d}$ where wave crests approaching the shoreline after $410 \mathrm{~s}$ are slowed down by the strong seaward direct flux driven by the backwash phase of a large swash event.

Spectra of free surface at the generation and of swash oscillations are plotted in Figure 3. The upper band of swash has a spectral decay that takes the form $f^{-b}$, where $b$ is the slope in the log-log plot, suggesting saturation (Ruessink et al., 1998). The spectral roll-off ranges between $f^{-4}$ for large $\xi_{0}$, Figure 3f, and slightly smaller values $\left(f^{-3.5}\right.$, Figure $\left.3 \mathrm{e}\right)$ for more dissipative conditions. Saturation is not limited to incident frequencies but extends to IG frequencies, especially for the most dissipative conditions. Figure 3 also shows how different $\gamma$ values yield different distribution of bound wave energy. Small values of frequency spread (large $\gamma$ ) are associated with long wave groups forcing a bound wave field whose energy is concentrated in the lower bands of the spectrum (black lines in Figures $3 \mathrm{c}$ and 3d). 


$\nabla \quad \gamma=1 \quad+\gamma=3.3 \quad \times \quad \gamma=8 \quad \Delta \quad \gamma=13$
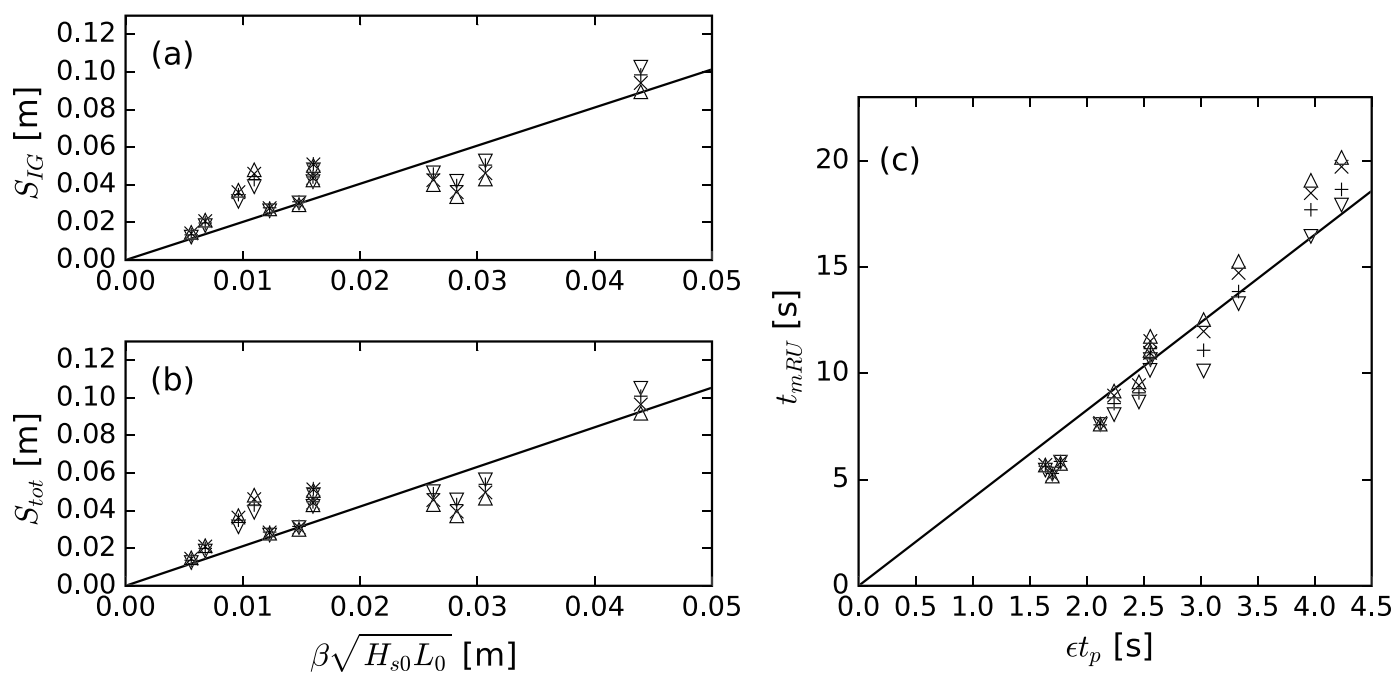

Figure 4. (a) Infragravity swash $S_{\text {IG }}$ versus $\beta \sqrt{H_{s 0} L_{0}}$. (b) Total swash $S_{\text {tot }}$ versus $\beta \sqrt{H_{s 0} L_{0}}$. (c) Mean swash period $t_{\mathrm{mRU}}$ versus $\epsilon t_{p}$. Solid lines in (a)-(c) represent the best linear fits.

The significant total swash $S_{\text {tot }}$ and the significant IG swash $S_{\text {IG }}$ are estimated from the swash energy spectra $E_{\mathrm{RU}}(f)$ as

$$
\begin{gathered}
S_{\mathrm{IG}}=4 \sqrt{\int_{0}^{f_{p} / 2} E_{\mathrm{RU}}(f) \mathrm{d} f}, \\
S_{\mathrm{tot}}=4 \sqrt{\int_{0}^{\infty} E_{\mathrm{RU}}(f) \mathrm{d} f} .
\end{gathered}
$$

A significant dependence of $S_{\text {IG }}$ (equation (7)) and $S_{\text {tot }}$ (equation (8)) on the parameter $\beta \sqrt{H_{s 0} L_{0}}$ is observed (squared correlation coefficients $r^{2}$ are, respectively, 0.70 and 0.75); see Figures $4 \mathrm{a}$ and $4 \mathrm{~b}$. The best linear fits forced to pass through the origin are

$$
\begin{aligned}
& S_{\mathrm{IG}}=2.03 \beta \sqrt{H_{s 0} L_{0}}, \\
& S_{\mathrm{tot}}=2.11 \beta \sqrt{H_{s 0} L_{0}} .
\end{aligned}
$$

This dependence implies that the vertical scaling of swash is proportional to the Iribarren number as first suggested by Hunt, (1959; see also equation (3) of Tomas et al., 2016) and then confirmed by several studies (Cohn \& Ruggiero, 2016; Holman \& Sallenger, 1985; Ruggiero et al., 2004; Stockdon et al., 2006). Moreover, the dependence of $S_{\mathrm{IG}}$ on $\beta \sqrt{H_{s 0} L_{0}}$ is higher for broad-banded runs with $\gamma=1\left(r^{2}=0.81\right)$ with respect to more narrow-banded runs (e.g., $r^{2}=0.59$ for runs with $\gamma=13$ ). If $\beta$ is removed from equations (7) and (8), the correlation decreases for both $S_{\mathrm{IG}}$ and $S_{\text {tot }}$, consistent with studies suggesting that $\beta$ plays a relevant role in both high- and low-frequency swash dynamics (da Silva et al., 2018; Passarella et al., 2018; Ruggiero et al., 2004).

In these experiments the mean runup frequency $f_{\mathrm{mRU}}$ varies from $0.050 \mathrm{~Hz}$ (run R37) to $0.19 \mathrm{~Hz}$ (run R48). $f_{\mathrm{mRU}}$ is calculated as

$$
f_{\mathrm{mRU}}=\frac{m_{1}}{m_{0}},
$$

where $m_{n}$ is the $n$ th-order moment of the swash spectrum

$$
m_{n}=\int_{0}^{\infty} f^{n} E_{\mathrm{RU}}(f) \mathrm{d} f .
$$



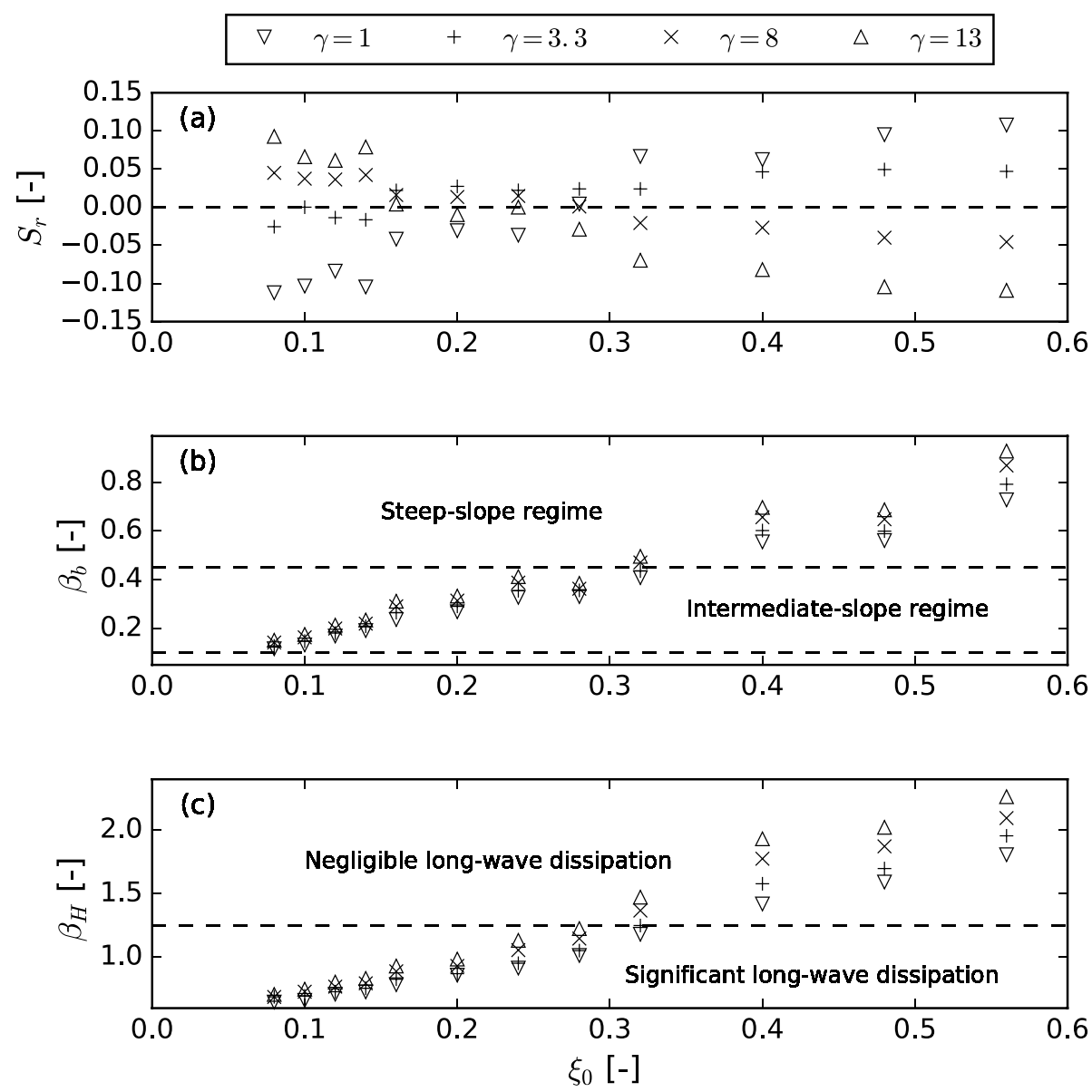

Figure 5. (a) Relative significant swash $S_{r}$ versus $\xi_{0}$. (b) Normalized slope parameter $\beta_{b}$ versus $\xi_{0}$. The lower and upper dashed lines distinguish between mild slope $\left(\beta_{b}<0.1\right)$, intermediate slope $\left(0.1 \leq \beta_{b}<0.45\right)$, and steep slope regimes $\left(\beta_{b} \geq 0.45\right)$. (c) Normalized slope parameter $\beta_{H}$ versus $\xi_{0}$. The horizontal dashed line indicates the expected onset of infragravity breaking at $\beta_{H}=1.25$.

The results reveal that the variation of the mean swash period $t_{\mathrm{mRU}}=1 / f_{\mathrm{mRU}}$ is well parametrized using the swash similarity parameter $\epsilon$ introduced by Brocchini and Baldock (2008); $r^{2}$ is 0.97 . The swash similarity parameter was first introduced by Brocchini and Baldock (2008) with the main aim of quantifying the degree of swash interactions in terms of offshore wave parameters; it is defined as

$$
\epsilon=\left(\frac{H_{s 0}}{g t_{p}^{2} \beta^{2}}\right)^{0.25}=(2 \pi)^{-0.25} \xi_{0}^{-0.5},
$$

where $g$ is gravity acceleration and it is highlighted the proportionality between $\epsilon$ and $\xi_{0}^{-0.5}$. The best linear fit forced to pass through the origin (Figure 4c) is

$$
t_{\mathrm{mRU}}=4.13\left(\frac{H_{s 0} t_{p}^{2}}{g \beta^{2}}\right)^{0.25}=4.13 \epsilon t_{p} .
$$

Although the lack of directional spread and the adoption of simplified bottom profiles reduce the complexity usually present in natural environments, in general terms, these numerical simulations provide features (such as the spectral decay within the saturated band of swash, the significant dependence of $S_{\text {IG }}$ on the parameter $\beta \sqrt{H_{s 0} L_{0}}$ and the proportionality between the mean swash period and the peak period multiplied by the swash similarity parameter) which appear consistent with field observations under dissipative conditions. This fact, in combination with the adoption of a numerical setup similar to that used by Ruju et al. (2014) for the simulation of the GLOBEX experiment, attests the reliability of the computed results for the investigation of swash dynamics under different wave and beach conditions. 
To focus on the influence of frequency spread, the relative significant swash $S_{r}$ is obtained as the difference between $S_{\mathrm{IG}}$ and $\overline{S_{\mathrm{IG}}}\left(S_{\mathrm{IG}}\right.$ averaged over the four runs characterized by the same $\left.\xi_{0}\right)$, divided by $\overline{S_{\mathrm{IG}}}$

$$
S_{r}=\frac{S_{\mathrm{IG}}-\overline{S_{\mathrm{IG}}}}{\overline{S_{\mathrm{IG}}}} .
$$

Figure 5a shows that, for $\xi_{0}$ values close to 0.24 , the effect of frequency spread on swash variability is weak, with $S_{r}$ lower than $7 \%$. This reference value of $\xi_{0}=0.24$ can be identified in the following way. First, for each value of $\gamma$, the relationship between $S_{r}$ and $\xi_{0}$ is modeled by means of linear regression analysis. By doing that, we have four regression lines (one line for each value of $\gamma$ ). Then, the reference value of $\xi_{0}=0.24$ is obtained as the average of the $\xi_{0}$ values at the intersection of the regression lines with the horizontal $\xi_{0}$ axis. Frequency spread tends to be more relevant for both larger and smaller $\xi_{0}$ reaching $23 \%$ of difference between the largest and the lowest $S_{\mathrm{IG}}$ with the same $\xi_{0}$. Moreover, we notice an inverted pattern between the more dissipative conditions $\left(\xi_{0}<0.24\right)$ in which $S_{\text {IG }}$ increases for increasing values of $\gamma$ and the more reflective conditions $\left(\xi_{0}>0.24\right)$ in which the opposite occurs.

Figures $5 \mathrm{~b}$ and $5 \mathrm{c}$ show how the bed slope parameters $\beta_{b}$ and $\beta_{H}$ (Battjes et al., 2004; van Dongeren et al., 2007) increase with both $\xi_{0}$ and $\gamma . \beta_{b}$ and $\beta_{H}$ are obtained as

$$
\begin{gathered}
\beta_{b}=\frac{\beta}{2 \pi \cdot f_{\mathrm{mIG}}^{+}} \cdot \sqrt{\frac{g}{h_{b}}}, \\
\beta_{H}=\frac{\beta}{2 \pi \cdot f_{\mathrm{mIG}}^{+}} \cdot \sqrt{\frac{g}{H_{\mathrm{sIG}}^{+}}}
\end{gathered}
$$

in which $h_{b}$ is the water depth at the breakpoint $x_{b}$. The mean frequency $f_{\mathrm{mIG}}^{+}$of the shoreward IG energy flux is calculated at $x_{b}$ in equation (14) and at the limit between the surf and the swash zone in equation (15). The incoming significant wave height of the IG band $H_{\text {sIG }}^{+}$is calculated at the limit between the surf and the swash zone. The $x_{b}$ location is defined as the point where $\left(H_{s} / H_{s 0}\right)^{2}=0.75, H_{s 0}$ being the significant wave height at the generation. The limit between surf and swash zone is defined here as the most shoreward location that remains wet for the entire simulation, allowing spectral analysis that is instead precluded in the intermittently wet/dry swash zone. In our case this limit is where water thickness never goes below $0.003 \mathrm{~m}$ (the same water thickness threshold used to identify the runup tip location). The formulation of Sheremet et al. (2002) is used for the separation of the shoreward and seaward components of the IG energy flux. The $\beta_{b}$ range includes values falling in an intermediate regime $\left(\beta_{b}<0.45\right.$ associated with low $\left.\xi_{0}\right)$ and values larger than 0.45 (associated with large $\xi_{0}$ ) falling in a steep slope regime (Battjes et al., 2004). Moreover, $\beta_{H}$ decreases with decreasing $\xi_{0}$, reaching values significantly smaller than 1.25 suggesting a considerable low-frequency energy dissipation in shallow water (van Dongeren et al., 2007) for cases with low $\xi_{0}$.

\section{Discussion}

\subsection{Propagation Regimes of Low-Frequency Waves Over a Sloping Bottom}

In this work, swash induced by normally incident waves shows a considerable dependence on the frequency spread of the offshore spectrum. Results show a $S_{\mathrm{IG}}$ increase for increasing frequency spread for Iribarren numbers larger than 0.24 . On the contrary, low Iribarren numbers $\left(\xi_{0}<0.24\right)$ yield an increase of $S_{\text {IG }}$ for decreasing frequency spread. To analyze the physical processes related to this behavior, let us consider a normally incident random wave field characterized by a zero directional spread. It forces a low-frequency bound wave field whose total energy mainly depends on the incoming SS energy (Sand, 1982; Bowers, 1993). However, broad-banded spectra force shorter subharmonic waves than those forced by narrow-banded spectra (Padilla \& Alsina, 2017). This fact has two main implications. First, broad-banded spectra yield relatively small values of the normalized bed slope parameter $\beta_{b}$, promoting the IG energy flux growth rate in the shoaling zone. Second, the relatively small values of $\beta_{H}$ associated with broad-banded spectra lead to strong dissipation rates for the IG energy flux under low Iribarren numbers.

The IG energy flux growth rate in the shoaling zone is observable in Figures $6 \mathrm{c}$ and $6 \mathrm{~d}$ showing that, prior to short-wave breaking, $E_{\mathrm{IG}}^{+}$increases stronger under broad-banded spectrum conditions (relatively low $\beta_{b}$ ). The breakpoint location $x_{b}$ is highlighted in Figures $6 \mathrm{a}$ and $6 \mathrm{~b}$ that show the evolution of incident (SS) 

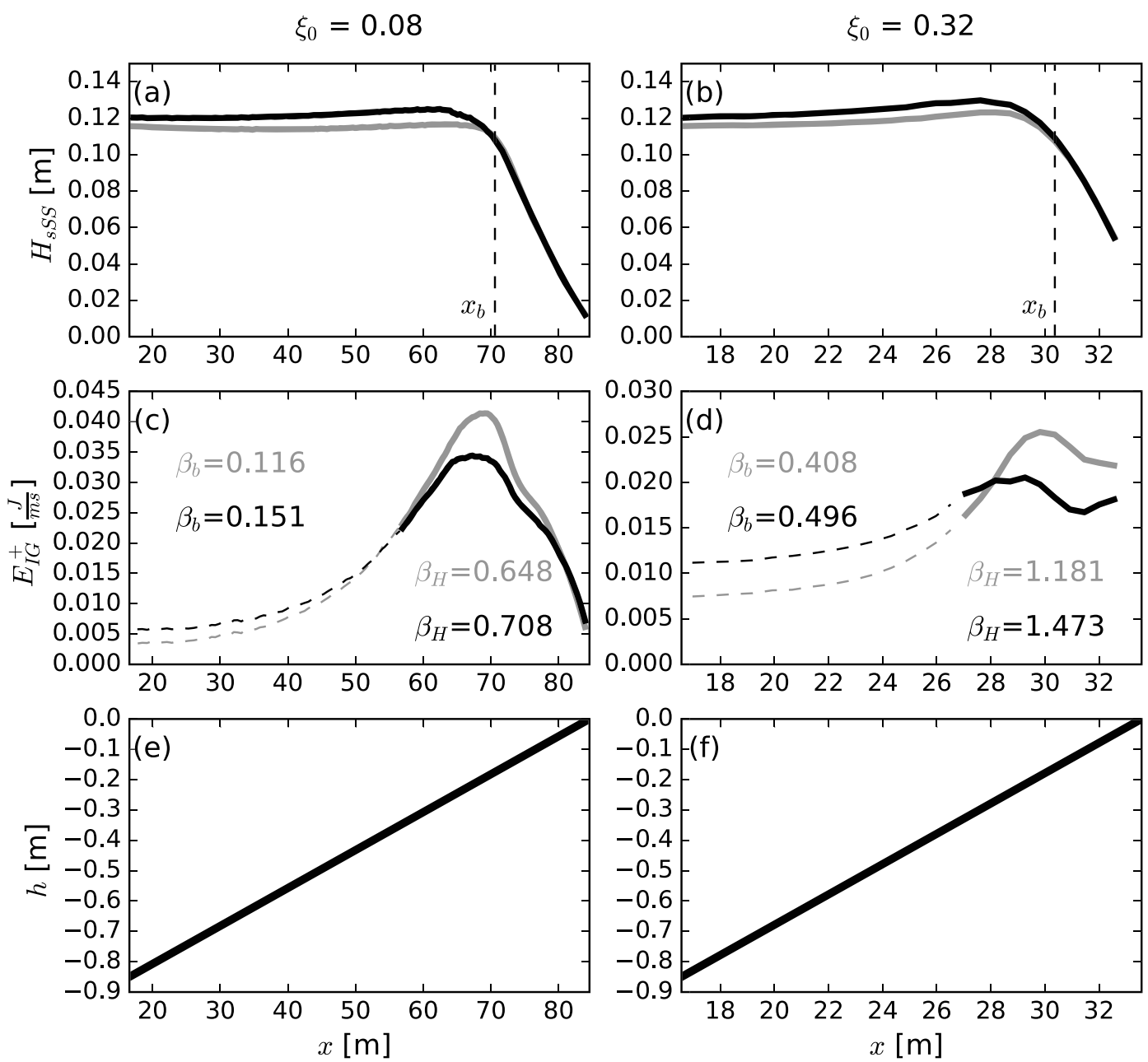

Figure 6. Cross-shore evolution of incident (sea-swell) significant wave height $H_{\text {sSS }}$ (a and b). The breakpoint location $x_{b}$ is indicated by the vertical dashed line. Cross-shore evolution of onshore infragravity (IG) energy flux $E_{\mathrm{IG}}^{+}(\mathrm{c}$ and d). Bottom profile (e and f). Gray and black lines in panels (a) and (c) represent runs R1 and R37 with, respectively, $\gamma=1$ and $\gamma=13$. Gray and black lines in panels (b) and (d) represent runs R9 and R45 with, respectively, $\gamma=1$ and $\gamma=13$. Solid lines in panels (c) and (d) extend over the region where the shallow water condition is satisfied for the entire infragravity band.

significant wave height $H_{\mathrm{sSS}}^{+}$. For moderately dissipative conditions $\left(\xi_{0}=0.32\right.$, Figure $\left.6 \mathrm{~d}\right)$, low-frequency waves experience a negligible or weak energy dissipation in shallow water as attested by the large values of $\beta_{H}$ in excess of 1.18. Under these conditions, the strong IG energy growth (low $\beta_{b}$ values) associated with broad-banded spectra plays the dominant role in determining the runup variability. At the limit between surf and swash zone, $E_{\mathrm{IG}}^{+}$associated with narrow-banded conditions is smaller than $E_{\mathrm{IG}}^{+}$associated with broad-banded conditions. These results suggest that an increase of the frequency spread leads to an increase of $S_{\mathrm{IG}}$ oscillations for the simulated runs with $\xi_{0}>0.24$ (observable in Figure 5a). On the contrary, for very low Iribarren numbers $\left(\xi_{0}=0.08\right.$, Figure $6 \mathrm{c}$ ), the low-frequency wave field dissipates in shallow water (Inch et al., 2017; van Dongeren et al., 2007): both narrow-banded and broad-banded spectra lead to $\beta_{H}$ values lower than 0.8. However, the smaller values of $\beta_{H}$ result in stronger dissipation rates for the $I G$ energy flux forced by the broad-banded spectrum of run R1. This dissipative process eventually overturns the stronger energy flux enhancement prior to the breakpoint: at the limit between surf and swash zone, $E_{\mathrm{IG}}^{+}$associated with narrow-banded conditions is larger than $E_{\mathrm{IG}}^{+}$associated with broad-banded conditions. This explains why a decrease of the frequency spread leads to a $S_{\text {IG }}$ increase for runs characterized by extremely dissipative conditions $\left(\xi_{0}<0.24\right.$, observable in Figure 5a). At the same time, we point out that, although $E_{\mathrm{IG}}^{+}$is a useful parameter characterizing the hydrodynamic forcing at the seaward boundary of the swash zone, under low Iribarren numbers IG energy dissipation is likely to continue to occur in the swash zone. That is the reason 

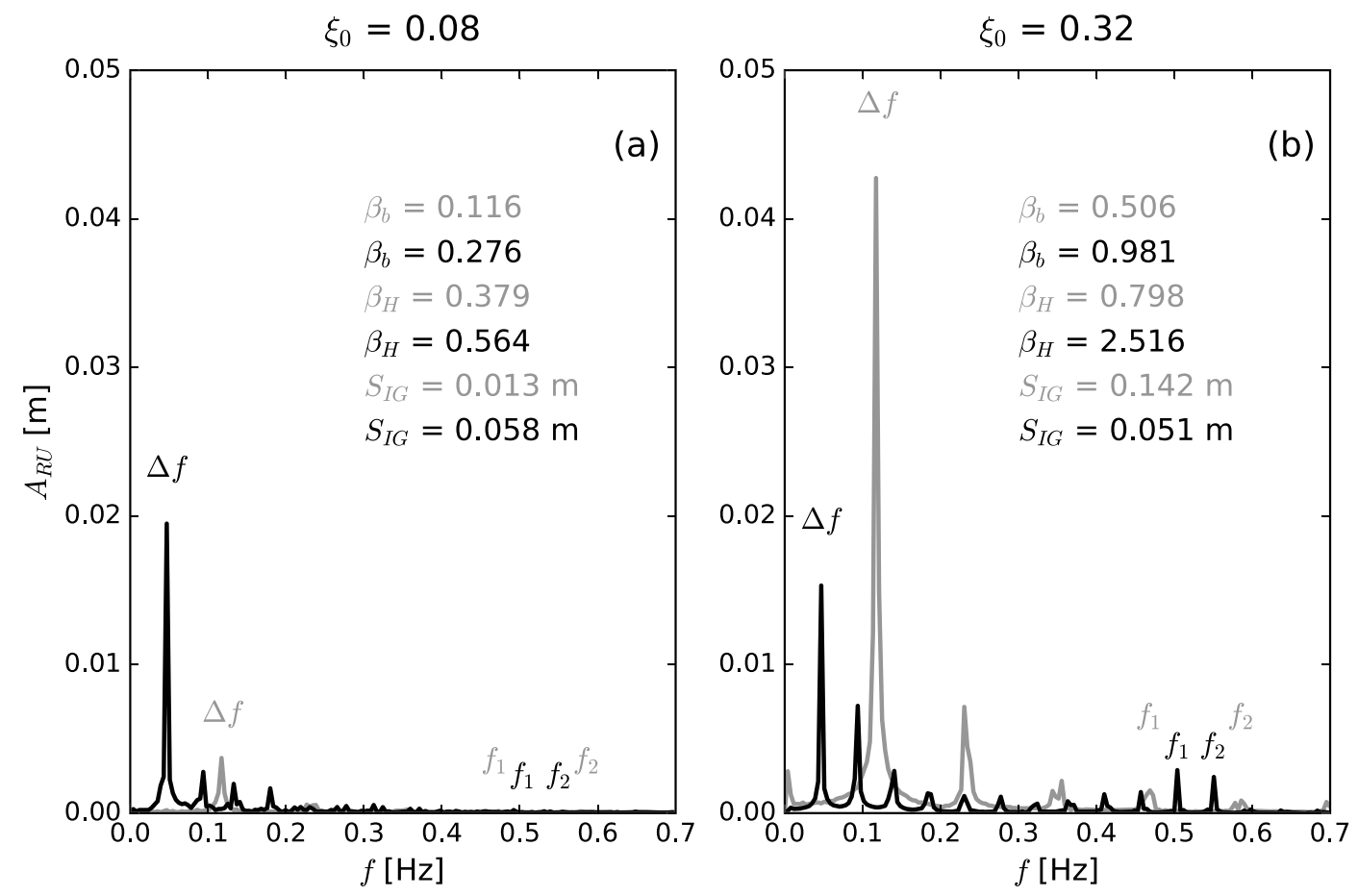

Figure 7. Runup amplitude spectra $A_{\mathrm{RU}}$ induced by bichromatic conditions with low (a) and high (b) Iribarren number $\xi_{0}$. Gray and black lines in panel (a) represent, respectively, runs B1 (large $\Delta f$ ) and B37 (small $\Delta f$ ). Gray and black lines in panel (b) represent, respectively, runs B9 (large $\Delta f$ ) and B45 (small $\Delta f$ ).

that, in our results, small differences in $E_{\mathrm{IG}}^{+}$can be amplified by swash zone processes and eventually lead to more significant differences in $S_{\mathrm{IG}}$.

With the main purpose of testing the validity of the findings obtained from the analysis of random wave cases, we run four additional bichromatic wave cases. Since they force a low-frequency wave field whose energy is concentrated around one incoming frequency, bichromatic wave cases can facilitate the interpretation of results bringing straightforward insight into the processes under investigation. These simulations show that the runup response induced by bichromatic wave forcing is analogous to that observed with the random wave cases; see Figure 7. For $\xi_{0}=0.32, S_{\text {IG }}$ induced by run B9 (large $\Delta f$ ) is larger than that of run B45 (small $\Delta f$ ). This difference in $S_{\text {IG }}$ seems to be related to the different magnitudes of low-frequency wave growth attested by the $\beta_{b}$ values in the two runs (run B9 has $\beta_{b}=0.506$, whereas run B45 has $\beta_{b}=0.981$ ). Figures $8 \mathrm{c}$ and $8 \mathrm{~d}$ show the cross-shore evolution of the onshore energy spectra, highlighting the larger amount of energy that reaches the swash zone in run B9 with respect to run B45. The opposite occurs for

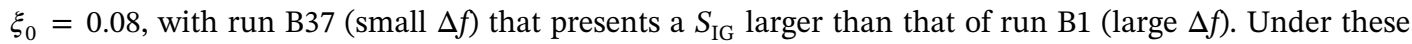
conditions, the low values of $\beta_{H}$ (run $\mathrm{B} 1$ has $\beta_{b}=0.379$, whereas run $\mathrm{B} 37$ has $\beta_{b}=0.564$ ) suggest that the shorter the low-frequency waves, the larger the energy dissipation in shallow water and thus the smaller $S_{\text {IG }}$ (see Figures $8 \mathrm{a}$ and $8 \mathrm{~b}$ ). It is worth mentioning that, possibly due the concentration of bound wave energy around a single frequency, the variability of $S_{\mathrm{IG}}$ for the bichromatic cases with same $\xi_{0}$ is more pronounced than that of the random waves cases.

\subsection{Connection With GF12}

The observed increase of $S_{\text {IG }}$ for increasing frequency spread values under moderately dissipative conditions is consistent with the findings of GF12. In that work, they ascribed this behavior to the change in the amount of bound wave energy induced by different frequency spread values under directionally spread waves. In fact, they suggested that large coupling coefficients associated with large frequency differences between pairs of SS components eventually yield large $S_{\mathrm{IG}}$ oscillations. In our study, the unidirectionality of the wave field simplifies the problem since in this case the bound wave energy amount does not depend on the frequency spread (Sand, 1982). Thus, GF12 reasoning cannot be applied to explain the $S_{\text {IG }}$ variability observed in our results. On the contrary, the strong low-frequency energy enhancement in the shoaling zone associated with broad-banded spectra (that is the key process explaining the $S_{\text {IG }}$ behavior observed 


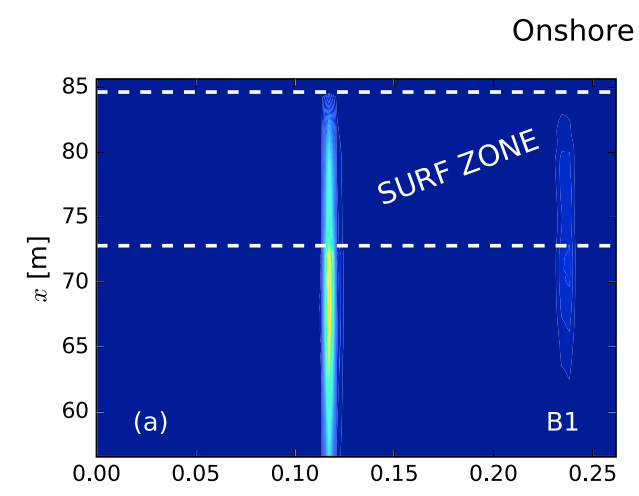

$$
\text { nergy density }\left[\mathrm{m}^{2} / \mathrm{Hz}\right]
$$
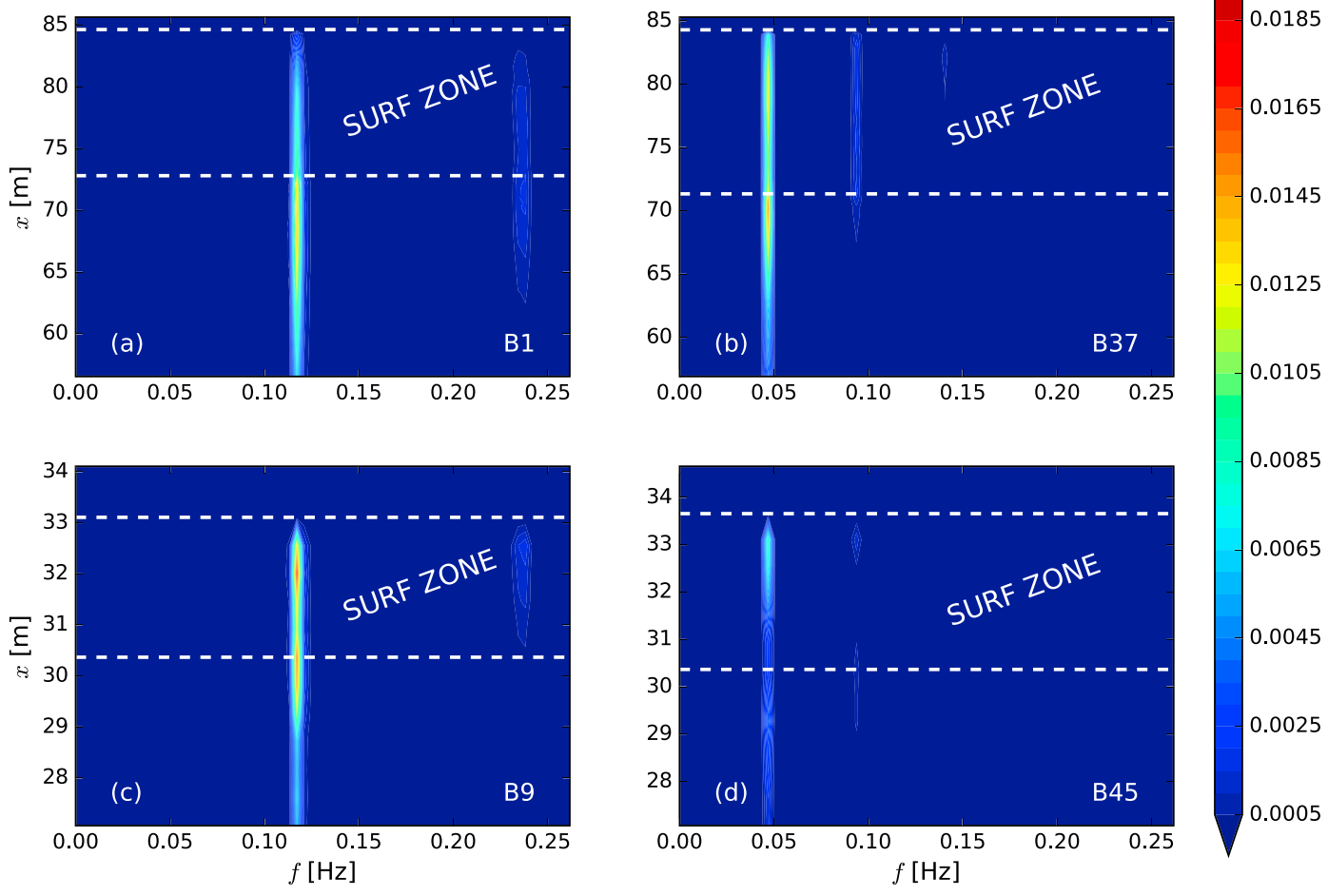

Figure 8. (a-d) Cross-shore evolution of onshore energy spectrum. The horizontal dashed lines indicate the seaward and shoreward limits of the short-wave surf zone.

in our work under moderately dissipative conditions) is expected to occur both under unidirectional and multidirectional waves.

In contrast with our results, GF12 did not report an increase of $S_{\mathrm{IG}}$ for decreasing frequency spread under extremely dissipative conditions. This disparity may be ascribed to three main reasons. First, they considered a different $\xi_{0}$ range. Second, the reduction of bound low-frequency energy under multidirectional waves implies that low-frequency energy dissipation in shallow water occurs at lower $\xi_{0}$ values. In other words, a given $\xi_{0}$ is expected to yield larger values of $\beta_{H}$ under multidirectional waves than under unidirectional waves. We argue that this would shift the inversion of the $S_{\text {IG }}$ pattern to Iribarren numbers lower than the 0.24 value reported here. Finally, the two relevant processes associated with an increase of the frequency spread under multidirectional waves (the increase of the bound wave energy identified by GF12 and the stronger energy dissipation in shallow water identified in this study) counteract each other under extremely dissipative conditions possibly leading to a small variability of $S_{\mathrm{IG}}$.

\subsection{Relevance of Directional Spread}

Due to the assumption of unidirectional waves, the findings presented in this work are not expected to exhaustively describe $S_{\mathrm{IG}}$ variability under natural wave conditions characterized by a wide range of directional spread values. In natural environments, narrow frequency and directional distributions are generally associated with swell waves, whereas young sea states are usually broad-banded and characterized by a high directional spread. By including a second-order function into the expression for long-wave elevations, Sand (1982) showed that, since long-wave directions are determined by the difference of the primary wave number vectors, the spread of the long waves is larger than that of the short waves. Moreover (for a given frequency spread value), wave groups with large directional spreads force smaller long waves than those forced by wave groups with small directional spreads. This fact seems to support the expected increase of $S_{\mathrm{IG}}$ for decreasing offshore directional spread Guza and Feddersen (2012). The scenario complicates if we allow also the frequency spread to vary together with the directional spread. In this respects, the results of Sand (1982) suggest that, considering two sea states with different directional and frequency spreads, it is not assured that the one with smaller directional spread will force larger long waves. In fact, for directionally spread waves the coupling coefficient increases as frequency spread increases. For instance, Figure 4 of 
Sand (1982) shows that the second-order function for a wave group with frequency spread $(\mathrm{d} f / f)=0.3$ and directional spread $(\mathrm{d} \theta)=20^{\circ}$ is larger than that for a wave group with delta $\mathrm{d} f / f=0.1$ and $\mathrm{d} \theta=10^{\circ}$. This is also in agreement with Bowers (1993) who stated that long waves are less sensitive to directional spread as this parameter increases.

Long-period swash oscillations induced by directional waves are sensitive to the offshore frequency spread not only because it plays a role in defining the forced long-wave field but also because it can determine different long-wave propagation regimes in the surf zone, as shown in this paper. Although in this work we address only the unidirectional wave scenario, the findings presented here provide an important insight into low-frequency swash dynamics. Moreover, we expect that they can also represent a relevant contribution toward a general formulation able to assess $S_{\mathrm{IG}}$ variability under a wide range of wave forcing. In this context, further research is needed to evaluate the possibility of combining the findings provided by previous work with those presented here in a single $S_{\mathrm{IG}}$ formulation that includes the effect of spectral shape parameters.

\section{Conclusions}

Numerical simulations show an IG swash variability induced by incident wave frequency spread with a pattern that inverts over two Iribarren number ranges. This behavior can be understood by looking at how the distribution of low-frequency wave energy affects two key processes that determine IG swash oscillations $S_{\text {IG }}$ under dissipative conditions: low-frequency energy growth in the shoaling zone (controlled by $\beta_{b}$ ) and low-frequency energy dissipation in shallow water (controlled by $\beta_{H}$ ). Larger frequency spreads force shorter low-frequency waves, thus yielding stronger low-frequency energy growths in the shoaling zone (smaller $\beta_{b}$ ). This process leads to an increase of $S_{\mathrm{IG}}$ for increasing frequency spreads under relatively large Iribarren numbers $\left(0.24<\xi_{0}<0.56\right)$ associated with a negligible or weak low-frequency energy dissipation in shallow water. Under extremely dissipative conditions $\left(\xi_{0}<0.24\right)$, the significant low-frequency energy dissipation in shallow water ( small $\beta_{H}$ ) associated with large frequency spreads overturns the strong low-frequency energy growth in the shoaling zone eventually leading to a decrease of $S_{\text {IG }}$ for increasing frequency spreads.

Acknowledgments

This work has been funded under (1) the RETOS INVESTIGACION 2014 (Grant BIA2014-59718-R) program of the Spanish Ministry of Economy and Competitiveness and (2) the NEPTUNE 2 project, L. R. 7/2007 by Regione Autonoma della Sardegna. Data used in this research are available online (ftp://ftp.ihcantabria.com/; Username: rujua-r; password: qMGx4s0J). We acknowledge the two reviewers for providing constructive comments on our manuscript. Giovanni Coco and Robert Guza are thanked for insightful discussions.

\section{References}

Ardhuin, F., Rawat, A., \& Aucan, J. (2014). A numerical model for free infragravity waves: Definition and validation at regional and global scales. Ocean Modelling, 77, 20-32. https://doi.org/10.1016/j.ocemod.2014.02.006

Baldock, T. E. (2006). Long wave generation by the shoaling and breaking of transient wave groups on a beach. Proceedings of the Royal Society of London A: Mathematical, Physical and Engineering Sciences, 462(2070), 1853-1876. https://doi.org/10.1098/rspa.2005.1642

Baldock, T. E., \& Huntley, D. A. (2002). Long-wave forcing by the breaking of random gravity waves on a beach, Proceedings of the Royal Society of London A: Mathematical. Physical and Engineering Sciences, 458(2025), 2177-2201. https://doi.org/10.1098/rspa.2002.0962

Baldock, T., Huntley, D., Bird, P., O'Hare, T., \& Bullock, G. (2000). Breakpoint generated surf beat induced by bichromatic wave groups. Coastal Engineering, 39(2), 213-242. https://doi.org/10.1016/S0378-3839(99)00061-7

Barnes, M. P., \& Baldock, T. E. (2010). A lagrangian model for boundary layer growth and bed shear stress in the swash zone. Coastal Engineering, 57(4), 385-396. https://doi.org/10.1016/j.coastaleng.2009.11.009

Battjes, J. A., Bakkenes, H. J., Janssen, T. T., \& van Dongeren, A. R. (2004). Shoaling of subharmonic gravity waves. Journal of Geophysical Research, 109, C02009. https://doi.org/10.1029/2003JC001863

Bowers, E. C. (1993). Low frequency waves in intermediate water depths. In Coastal engineering 1992. Venice, Italy. https://doi.org/10. $1061 / 9780872629332.062$

Brocchini, M., \& Baldock, T. E. (2008). Recent advances in modeling swash zone dynamics: Influence of surf-swash interaction on nearshore hydrodynamics and morphodynamics. Reviews of Geophysics, 46, RG3003. https://doi.org/10.1029/2006RG000215

Butt, T., \& Russell, P. (2000). Hydrodynamics and cross-shore sediment transport in the swash-zone of natural beaches: A review. Journal of Coastal Research, 16(2), 255-268. Retrieved from http://www.jstor.org/stable/4300034

Chardon-Maldonado, P., Pintado-Patino, J. C., \& Puleo, J. A. (2016). Advances in swash-zone research: Small-scale hydrodynamic and sediment transport processes. Coastal Engineering, 115, 8-25. https://doi.org/10.1016/j.coastaleng.2015.10.008

Cohn, N., \& Ruggiero, P. (2016). The influence of seasonal to interannual nearshore profile variability on extreme water levels: Modeling wave runup on dissipative beaches. Coastal Engineering, 115, 79-92. https://doi.org/10.1016/j.coastaleng.2016.01.006

da Silva, P. G., Medina, R., Gonzalez, M., \& Garnier, R. (2018). Infragravity swash parameterization on beaches: The role of the profile shape and the morphodynamic beach state. Coastal Engineering, 136, 41-55. https://doi.org/10.1016/j.coastaleng.2018.02.002

de Bakker, A. T. M., Herbers, T. H. C., Smit, P. B., Tissier, M. F. S., \& Ruessink, B. G. (2015). Nonlinear infragravity wave interactions on a gently sloping laboratory beach. Journal of Physical Oceanography, 45(2), 589-605. https://doi.org/10.1175/JPO-D-14-0186.1

de Bakker, A. T. M., Tissier, M. F. S., \& Ruessink, B. G. (2016). Beach steepness effects on nonlinear infragravity-wave interactions: A numerical study. Journal of Geophysical Research: Oceans, 121, 554-570. https://doi.org/10.1002/2015JC011268

Elfrink, B., \& Baldock, T. (2002). Hydrodynamics and sediment transport in the swash zone: A review and perspectives. Coastal Engineering, 45(3), 149-167. https://doi.org/10.1016/S0378-3839(02)00032-7

Fiedler, J. W., Brodie, K. L., McNinch, J. E., \& Guza, R. T. (2015). Observations of runup and energy flux on a low-slope beach with high-energy, long-period ocean swell. Geophysical Research Letters, 42, 9933-9941. https://doi.org/10.1002/2015GL066124 
Fiedler, J. W., Smit, P. B., Brodie, K. L., McNinch, J., \& Guza, R. T. (2018). Numerical modeling of wave runup on steep and mildly sloping natural beaches. Coastal Engineering, 131, 106-113. https://doi.org/10.1016/j.coastaleng.2017.09.004

Fiedler, J. W., Smit, P. B., Brodie, K. L., McNinch, J., \& Guza, R. (2019). The offshore boundary condition in surf zone modeling. Coastal Engineering, 143, 12-20. https://doi.org/10.1016/j.coastaleng.2018.10.014

Goda, Y. (1970). Numerical experiments on wave statistics with spectral simulations. Report of the Port and Harbour Research Institute, 9(3), 3-57.

Guedes, R. M. C., Bryan, K. R., Coco, G., \& Holman, R. A. (2011). The effects of tides on swash statistics on an intermediate beach. Journal of Geophysical Research, 116, C04008. https://doi.org/10.1029/2010JC006660

Guza, R. T., \& Feddersen, F. (2012). Effect of wave frequency and directional spread on shoreline runup. Geophysical Research Letters, 39, L11607. https://doi.org/10.1029/2012GL051959

Guza, R. T., \& Thornton, E. B. (1982). Swash oscillations on a natural beach. Journal of Geophysical Research, 87(C1), 483-491. https://doi. org/10.1029/JC087iC01p00483

Herbers, T. H. C., Elgar, S., \& Guza, R. T. (1995). Generation and propagation of infragravity waves. Journal of Geophysical Research, 100(C12), 24,863-24,872. https://doi.org/10.1029/95JC02680

Holland, K. T., Raubenheimer, B., Guza, R. T., \& Holman, R. A. (1995). Runup kinematics on a natural beach. Journal of Geophysical Research, 100(C3), 4985-4993. https://doi.org/10.1029/94JC02664

Holman, R. A., \& Sallenger, A. H. Jr. (1985). Setup and swash on a natural beach. Journal of Geophysical Research, 90(C1), 945-953. https:// doi.org/10.1029/JC090iC01p00945

Horn, D. P. (2002). Beach groundwater dynamics. Geomorphology, 48(1), 121-146. https://doi.org/10.1016/S0169-555X(02)00178-2

Hunt, J. (1959). Design of seawalls and breakwaters. Journal of the Waterways and Harbors Division, 85, $123-152$.

Inch, K., Davidson, M., Masselink, G., \& Russell, P. (2017). Observations of nearshore infragravity wave dynamics under high energy swell and wind-wave conditions. Continental Shelf Research, 138, 19-31. https://doi.org/10.1016/j.csr.2017.02.010

Lara, J. L., Ruju, A., \& Losada, I. J. (2011). Reynolds averaged Navier-Stokes modelling of long waves induced by a transient wave group on a beach. Proceedings of the Royal Society of London A: Mathematical, Physical and Engineering Sciences, 467(2129), 1215-1242. https:// doi.org/10.1098/rspa.2010.0331

Lo, J. M., \& Dean, R. G. (1995). Long waves due to interactions beneath wave groups. Journal of Waterway, Port, Coastal, and Ocean Engineering, 121(6), 317-325. https://doi.org/10.1061/(ASCE)0733-950X(1995)121:6(317)

Longuet-Higgins, M. S., \& Stewart, R. W. (1962). Radiation stress and mass transport in gravity waves, with application to surf beats. Journal of Fluid Mechanics, 13(4), 481-504. https://doi.org/10.1017/S0022112062000877

McArdle, S. B., \& McLachlan, A. (1992). Sand beach ecology: Swash features relevant to the macrofauna. Journal of Coastal Research, 8(2), 398-407. Retrieved from http://www.jstor.org/stable/4297985

Mendes, D., Pinto, J. P., Pires-Silva, A. A., \& Fortunato, A. B. (2018). Infragravity wave energy changes on a dissipative barred beach: A numerical study. Coastal Engineering, 140, 136-146. https://doi.org/10.1016/j.coastaleng.2018.07.005

Nielsen, P., \& Baldock, T. E. (2010). N-Shaped surf beat understood in terms of transient forced long waves. Coastal Engineering, 57(1), 71-73. https://doi.org/10.1016/j.coastaleng.2009.09.003

Padilla, E. M., \& Alsina, J. M. (2017). Transfer and dissipation of energy during wave group propagation on a gentle beach slope. Journal of Geophysical Research: Oceans, 122, 6773-6794. https://doi.org/10.1002/2017JC012703

Passarella, M., Goldstein, E. B., De Muro, S., \& Coco, G. (2018). The use of genetic programming to develop a predictor of swash excursion on sandy beaches. Natural Hazards and Earth System Sciences, 18(2), 599-611. https://doi.org/10.5194/nhess-18-599-2018

Puleo, J. A., \& Holland, K. T. (2001). Estimating swash zone friction coefficients on a sandy beach. Coastal Engineering, 43(1), 25-40. https://doi.org/10.1016/S0378-3839(01)00004-7

Raubenheimer, B., \& Guza, R. T. (1996). Observations and predictions of run-up. Journal of Geophysical Research, 101(C11), $25,575-25,587$. https://doi.org/10.1029/96JC02432

Ruessink, G., Kleinhans, M. G., \& van den Beukel, P. G. L. (1998). Observations of swash under highly dissipative conditions. Journal of Geophysical Research, 103(C2), 3111-3118. https://doi.org/10.1029/97JC02791

Ruessink, B. G., Michallet, H., Bonneton, P., Mouaze, D., Lara, J., Silva, P. A., \& Wellens, P. (2013). Globex: Wave dynamics on a gently sloping laboratory beach, Proceedings of the 7th International Conference on Coastal Dynamics (pp. 1351-1362). Arcachon (France):

Ruggiero, P., Holman, R. A., \& Beach, R. A. (2004). Wave run-up on a high-energy dissipative beach. Journal of Geophysical Research, 109, C06025. https://doi.org/10.1029/2003JC002160

Ruju, A., Conley, D., Masselink, G., Austin, M., Puleo, J., Lanckriet, T., \& Foster, D. (2016). Boundary layer dynamics in the swash zone under large-scale laboratory conditions. Coastal Engineering, 113, 47-61. https://doi.org/10.1016/j.coastaleng.2015.08.001

Ruju, A., Lara, J. L., \& Losada, I. J. (2012). Radiation stress and low-frequency energy balance within the surf zone: A numerical approach. Coastal Engineering, 68, 44-55. https://doi.org/10.1016/j.coastaleng.2012.05.003

Ruju, A., Lara, J. L., \& Losada, I. J. (2014). Numerical analysis of run-up oscillations under dissipative conditions. Coastal Engineering, 86, 45-56. https://doi.org/10.1016/j.coastaleng.2014.01.010

Sand, S. E. (1982). Long waves in directional seas. Coastal Engineering, 6(3), 195-208. https://doi.org/10.1016/0378-3839(82)90018-7

Senechal, N., Coco, G., Bryan, K. R., \& Holman, R. A. (2011). Wave runup during extreme storm conditions. Journal of Geophysical Research, 116, C07032. https://doi.org/10.1029/2010JC006819

Sheremet, A., Guza, R. T., Elgar, S., \& Herbers, T. H. C. (2002). Observations of nearshore infragravity waves: Seaward and shoreward propagating components. Journal of Geophysical Research, 107(C8), 3095. https://doi.org/10.1029/2001JC000970

Smit, P. B., Janssen, T. T., Herbers, T. H. C., Taira, T., \& Romanowicz, B. A. (2018). Infragravity wave radiation across the shelf break. Journal of Geophysical Research: Oceans, 123, 4483-4490. https://doi.org/10.1029/2018JC013986

Stockdon, H. F., Holman, R. A., Howd, P. A., \& Sallenger, A. H. (2006). Empirical parameterization of setup, swash, and runup. Coastal Engineering, 53(7), 573-588. https://doi.org/10.1016/j.coastaleng.2005.12.005

Symonds, G., Huntley, D. A., \& Bowen, A. J. (1982). Two-dimensional surf beat: Long wave generation by a time-varying breakpoint. Journal of Geophysical Research, 87(C1), 492-498. https://doi.org/10.1029/JC087iC01p00492

Tomas, A., Mendez, F. J., Medina, R., Jaime, F. F., Higuera, P., Lara, J. L., et al. (2016). A methodology to estimate wave-induced coastal flooding hazard maps in Spain. Journal of Flood Risk Management, 9(3), 289-305. https://doi.org/10.1111/jfr3.12198

Turner, I. L., \& Masselink, G. (1998). Swash infiltration-exfiltration and sediment transport. Journal of Geophysical Research, 103(C13), 30,813-30,824. https://doi.org/10.1029/98JC02606 
van Dongeren, A., Battjes, J., Janssen, T., van Noorloos, J., Steenhauer, K., Steenbergen, G., \& Reniers, A. (2007). Shoaling and shoreline dissipation of low-frequency waves. Journal of Geophysical Research, 112, C02011. https://doi.org/10.1029/2006JC003701

Vousdoukas, M. I., Wziatek, D., \& Almeida, L. P. (2012). Coastal vulnerability assessment based on video wave run-up observations at a mesotidal, steep-sloped beach. Ocean Dynamics, 62(1), 123-137. https://doi.org/10.1007/s10236-011-0480-x

Zijlema, M., Stelling, G., \& Smit, P. (2011). Swash: An operational public domain code for simulating wave fields and rapidly varied flows in coastal waters. Coastal Engineering, 58(10), 992-1012. https://doi.org/10.1016/j.coastaleng.2011.05.015 